\title{
Self-rated health in Pakistan: results of a national health survey Khabir Ahmad ${ }^{1,2}$, Tazeen H Jafar*1,3 and Nish Chaturvedi ${ }^{4}$
}

Address: ${ }^{1}$ Clinical Epidemiology Unit, Department of Community Health Sciences, Aga Khan University, Karachi, Pakistan, ${ }^{2}$ Section of Ophthalmology, Department of Surgery, Aga Khan University, Karachi, Pakistan, ${ }^{3}$ Section of Nephrology, Department of Medicine, Aga Khan University, Karachi, Pakistan, and Division of Nephrology, Department of Medicine, Tufts-New England Medical Center, Tufts University Medical School, Boston, MA, USA and ${ }^{4}$ Department of Epidemiology and Public Health, Imperial College of Medicine at St. Mary's, UK

Email: Khabir Ahmad - drkhabir@hotmail.com; Tazeen H Jafar* - tazeen.jafar@aku.edu; Nish Chaturvedi - n.chaturvedi@imperial.ac.uk

* Corresponding author

Published: 19 May 2005

BMC Public Health 2005, 5:5 I doi: |0.| |86/|47|-2458-5-5 |
Received: 30 November 2004

Accepted: 19 May 2005

This article is available from: http://www.biomedcentral.com/I47I-2458/5/5 I

(C) 2005 Ahmad et al; licensee BioMed Central Ltd.

This is an Open Access article distributed under the terms of the Creative Commons Attribution License (http://creativecommons.org/licenses/by/2.0), which permits unrestricted use, distribution, and reproduction in any medium, provided the original work is properly cited.

\begin{abstract}
Background: Self-rated health (SRH) is a robust predictor of mortality. In UK, migrants of South Asian descent, compared to native Caucasian populations, have substantially poorer SRH. Despite its validation among migrant South Asian populations and its popularity in developed countries as a useful public health tool, the SRH scale has not been used at a population level in countries in South Asia. We determined the prevalence of and risk factors for poor/fair SRH among individuals aged $\geq 15$ years in Pakistan $(n=9442)$.
\end{abstract}

Methods: The National Health Survey of Pakistan was a cross-sectional population-based survey, conducted between 1990 and 1994, of 18 I 35 individuals aged 6 months and above; 9442 of them were aged $\geq 15$ years. Our main outcome was SRH which was assessed using the question: "Would you say your health in general is excellent, very good, good, fair, or poor?" SRH was dichotomized into poor/fair, and good (excellent, very good, or good).

Results: Overall $65.1 \%$ respondents $-51.3 \%$ men vs. $77.2 \%$ women - rated their health as poor/ fair. We found a significant interaction between sex and age $(\mathrm{p}<0.000 \mathrm{I})$. The interaction was due to the gender differences only in the ages 15-19 years, whereas poor/fair SRH at all older ages was more prevalent among women and increased at the same rate as it did among men. We also found province of dwelling, low or middle SES, literacy, rural dwelling and current tobacco use to be independently associated with poor/fair SRH.

Conclusion: This is the first study reporting on poor/fair SRH at a population-level in a South Asian country. The prevalence of poor/fair health in Pakistan, especially amongst women, is one of the worst ever reported, warranting immediate attention. Further research is needed to explain why women in Pakistan have, at all ages, poorer SRH than men.

\section{Background}

South Asia, home to over 1.5 billion people (a quarter of the world's population) has one of the worst health indicators in the world [1]. Around 34\% of the world's childhood deaths occur in this region, which also has unacceptably high rates of maternal deaths $[1,2]$. In addition, South Asia is also facing a growing burden of cardiovascular disease (CVD)[3]. South Asians, even if they live in developed countries, have substantially higher morbidity and mortality rates than the local majority populations 
Table I: The distribution of self-related health status and other characteristics among men and women aged 15 years and older in the first National Health Survey of Pakistan

\begin{tabular}{|c|c|c|c|c|}
\hline Variable & & Men $(n=44 \mid 4) \%$ & Women $(n=5028) \%$ & All $(n=9442) \%$ \\
\hline \multirow[t]{5}{*}{ Self-rated health status } & Excellent & 0.6 & 0.3 & 0.4 \\
\hline & Very good & 8.3 & 2.1 & 5.0 \\
\hline & Good & 39.8 & 20.4 & 29.5 \\
\hline & Fair & 37.0 & 39.4 & 38.3 \\
\hline & Poor & 14.3 & 37.8 & 26.8 \\
\hline \multirow[t]{5}{*}{ Age } & $<20$ & 18.1 & 16.9 & 17.4 \\
\hline & $20-29$ & 23.8 & 27.1 & 25.5 \\
\hline & $30-39$ & 18.8 & 20.3 & 19.6 \\
\hline & $40-49$ & 13.3 & 14.4 & 13.9 \\
\hline & $\geq 50$ & 26.1 & 21.4 & 23.6 \\
\hline \multirow[t]{2}{*}{ Dwelling } & Rural & 63.6 & 64.5 & 64.1 \\
\hline & Urban & 36.4 & 35.5 & 35.9 \\
\hline \multirow[t]{2}{*}{ Literacy } & Illiterate & 53.1 & 81.1 & 68.0 \\
\hline & Literate & 46.9 & 18.9 & 32.0 \\
\hline \multirow{3}{*}{$\begin{array}{l}\text { Socio Economic Status } \\
\text { (SES) }\end{array}$} & Low SES & 33.7 & 32.6 & 33.1 \\
\hline & Middle SES & 49.0 & 49.1 & 49.0 \\
\hline & High SES & 17.3 & 18.3 & 17.9 \\
\hline \multirow[t]{2}{*}{ Currently use tobacco } & No & 60.3 & 88.8 & 75.5 \\
\hline & Yes & 39.7 & 11.2 & 24.5 \\
\hline \multirow[t]{4}{*}{ Province } & Sindh & 20.7 & 21.2 & 20.9 \\
\hline & Punjab & 53.3 & 50.9 & 52.0 \\
\hline & NWFP & 15.5 & 15.7 & 15.6 \\
\hline & Balochistan & 10.6 & 12.3 & 11.5 \\
\hline \multirow[t]{5}{*}{ Marital status } & Never married & 31.2 & 19.6 & 25.1 \\
\hline & Married & 64.1 & 69.5 & 66.9 \\
\hline & Widowed/widower & 4.5 & 10.4 & 7.6 \\
\hline & Divorced & 0.2 & 0.3 & 0.2 \\
\hline & Separated & 0.1 & 0.2 & 0.2 \\
\hline \multirow[t]{2}{*}{ Hypertension } & Normal & 79.8 & 82.0 & 80.9 \\
\hline & Hypertensive & 20.2 & 18.0 & 19.1 \\
\hline
\end{tabular}

from CVD. Further, compared to native Caucasian populations, migrants of South Asian descent have substantially poorer self-rated health (SRH)[4] which is a robust predictor of key health outcomes, including mortality and morbidity [5]. Out of all South Asian ethnic subgroups in the UK, Pakistanis and Bangladeshis have the poorest SRH[4]. This is particularly striking, as South Asians largely migrate to the UK in search of employment, and should thus be subject to the healthy migrant effect.

Despite its popularity in developed countries as a useful public health tool and its validation among migrant South Asian populations[4], the SRH scale has not been used at a population level in countries in South Asia. SRH was assessed for the first time at a population level in the National Health Survey of Pakistan (NHSP)-1990-94. We analysed NHSP data to estimate the prevalence of and identify risk factors for poor/fair SRH among individuals aged $\geq 15$ years in Pakistan $(\mathrm{n}=9442)$.

\section{Methods}

NHSP's design is described in detail elsewhere[6,7]. Briefly, the NHSP was commissioned by the Pakistan Medical Research Council (PMRC), and conducted between 1990-1994, under the technical assistance of the United States National Center for Health Statistics. The 
Table 2: Unadjusted odds ratio for poor/fair self-rated health status for individuals aged I 5 years and older in the first National Health Survey of Pakistan

\begin{tabular}{|c|c|c|c|c|c|}
\hline Variable & & Total & $\begin{array}{l}\text { Individuals with } \\
\text { poor/fair SRH (\%) }\end{array}$ & $\begin{array}{l}\text { Unadjusted Odds ratio for } \\
\text { poor/fair SRH }(95 \% \mathrm{Cl})\end{array}$ & P-value \\
\hline Number of individuals & & 9373 & $6101(65.1)$ & & \\
\hline \multirow[t]{2}{*}{ Age } & $15-19$ & 1636 & $866(14.2)$ & 1.0 & $<0.0001$ \\
\hline & $\geq 20$ & 7737 & $5235(85.8)$ & $1.86(1.67,2.07)$ & \\
\hline \multirow[t]{2}{*}{ Sex } & Female & 4995 & $3856(63.2)$ & $3.22(2.94,3.5 \mathrm{I})$ & $<0.0001$ \\
\hline & Male & 4378 & $2245(36.8)$ & 1.0 & \\
\hline \multirow[t]{3}{*}{ Marital status } & Never married & 2239 & II $97(20.6)$ & 1.0 & $<0.0001$ \\
\hline & Married & 5980 & $4043(69.4)$ & $1.82(1.65,2.01)$ & \\
\hline & $\begin{array}{l}\text { Widow/widower/ } \\
\text { divorced/separated }\end{array}$ & 708 & $582(10.0)$ & $4.02(3.26,4.96)$ & \\
\hline \multirow[t]{2}{*}{ Dwelling } & Rural & 5995 & $4087(67.0)$ & $1.45(1.33,1.58)$ & $<0.0001$ \\
\hline & Urban & 3378 & $2014(33.0)$ & 1.0 & \\
\hline \multirow[t]{2}{*}{ Literacy } & Literate & 3012 & $1570(25.7)$ & 1.0 & $<0.0001$ \\
\hline & Illiterate & 6361 & $4531(74.3)$ & $2.27(2.08,2.49)$ & \\
\hline \multirow[t]{3}{*}{ Socioeconomic status (SES) } & Low SES & 3103 & $2228(36.5)$ & $1.81(1.59,2.04)$ & $<0.0001$ \\
\hline & Middle SES & 4592 & $2891(47.4)$ & $1.21(1.08,1.35)$ & \\
\hline & High SES & 1678 & $982(16.1)^{\prime}$ & 1.0 & \\
\hline \multirow[t]{4}{*}{ Province } & Punjab & 4858 & $4015(65.8)$ & $9.20(8.17,0.36)$ & $<0.0001$ \\
\hline & NWFP & 1468 & $684(11.2)$ & $1.69(1.47,1.94)$ & \\
\hline & Balochistan & 1074 & 729 (11.9) & $4.08(3.48,4.78)$ & \\
\hline & Sindh & 1973 & $673(11.0)$ & 1.0 & \\
\hline \multirow[t]{2}{*}{ Currently use tobacco } & Yes & 2307 & $1433(23.5)$ & $0.84(0.76,0.93)$ & $<0.01$ \\
\hline & No & 7066 & $4668(76.5)$ & 1.0 & \\
\hline \multirow[t]{2}{*}{ Hypertension } & Normal & 7522 & $4832(80.1)$ & 1.0 & $<0.01$ \\
\hline & Hypertensive & 1772 & $1203(19.9)$ & $1.18(1.05,1.31)$ & \\
\hline
\end{tabular}

design of the survey was a modification of United States' Third National Health and Nutrition Examination Survey (NHANES III). Using a two-stage stratified design, the NHSP was a nationwide household survey that collected information on health and nutritional indicators from a representative sample $(18,135$ individuals aged 6 months or older). Data collection involved the use of a questionnaire which had been validated in local languages. NHSP included an interview conducted at the participant's home by trained health workers, followed by a standardized physical examination in a well-equipped clinic by physicians.

Our primary outcome measure was SRH which was assessed using the question: "Would you say your health in general is excellent, very good, good, fair, or poor?" SRH was dichotomized into poor/fair and good (excellent, very good, or good). Household socioeconomic status (SES; high, middle or low) was defined on the basis of the number of material items owned (TV, bicycle, motorcycle, refrigerator, car, etc). Tobacco use (cigarettes, beddies, huqqa, chillum, and tobacco chewing) was dichotomized into current use or not. Respondents were asked, "Have you smoked at least 100 cigarettes or beddies during your entire life?" Those who replied "yes" were asked, "Do you smoke now?" Current smokers were persons who reported current smoking and having smoked at least 100 cigarettes or beddies during their lifetime. Respondents were also asked, "Have you chewed tobacco or used snuff at least 100 times during your entire life?" 


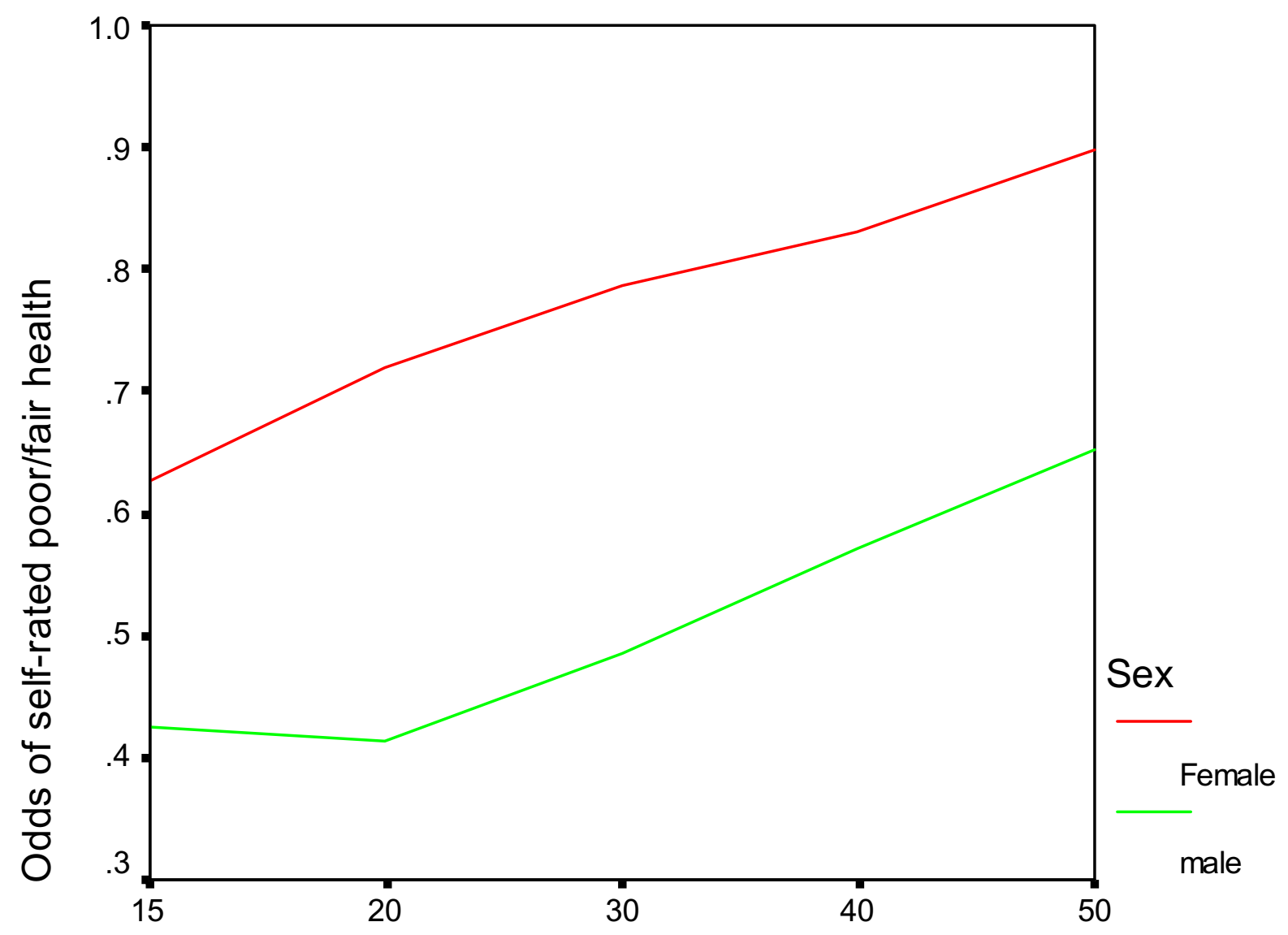

Age

Figure I

Graphic presentation of the association between poor/fair self-rated health and age by gender.

Those who said "yes" were asked, "Do you chew tobacco or use snuff now?" Those respondents who replied they did were reported as current tobacco chewers/snuff users.

Literacy was defined as the ability to read. There are four provinces in Pakistan: Punjab, Sindh, North West Frontier Province (NWFP) and Balochistan, each having its distinct culture, languages, and climate. Urban was defined as any area which had any of the following local government institutions at the time of 1981 population census: metropolitan corporation, municipal corporation, municipal committee, town committee, or cantonment board. All other areas were defined as rural.
Analyses were performed with the SPSS statistical package (version 10.0). Means and standard deviations were computed for continuous variables, while proportions and 95\% CIs for categorical variables. The association between poor/fair SRH and age, sex, literacy status, province of residence, area of residence (urban vs. rural), SES, marital status, hypertension, and current tobacco use was investigated, using univariate logistic regression. Variables that were associated with poor/fair health at p-value $<0.2$ at the univariate logistic regression analysis were considered for the final multivariate logistic model (Table 2). Factors that were included in the final model were sex-age interaction, province of living, area of living (urban vs. rural), literacy, SES, and current tobacco use. Tests for interactions between sex and other independent variables were per- 
Table 3: Adjusted odds ratio for poor/fair self-rated health status for individuals aged 15 years and older in the first National Health Survey of Pakistan

\begin{tabular}{lll}
\hline Variable & & Adjusted Odds ratio for poor/fair SRH (95\% CI) \\
\hline Male & $15-19$ years & 1.0 \\
& $\geq 20$ years & $1.37(1.14-1.64)$ \\
Female & $15-19$ years & $2.79(2.21-3.51)$ \\
& $\geq 20$ years & $7.60(6.23-9.27)$ \\
Dwelling & Rural & $1.25(1.11-1.39)$ \\
& Urban & 1.0 \\
Literacy & Literate & $1.33(1.17-1.50)$ \\
& Illiterate & 1.0 \\
Socioeconomic status (SES) & Low SES & $1.56(1.34-1.82)$ \\
& Middle SES & $1.17(1.02-1.35)$ \\
Province & High SES & 1.0 \\
& Punjab & $13.34(11.63-15.29)$ \\
& NWFP & $1.93(1.66-2.25)$ \\
Currently use tobacco & Balochistan & $4.52(3.79-5.39)$ \\
& Sindh & 1.0 \\
& Yes & $1.33(1.17-1.51)$ \\
\end{tabular}

formed. The interaction between sex and age was assessed first using age as a continuous variable. However, based on the plot of association between poor/fair SRH and age by gender (Fig 1), age was used as a categorical variable $(15-19$ years and $\geq 20$ years) in the final model.

\section{Results}

The overall agreement to be interviewed was $92.6 \%$. A total of 9442 individuals interviewed were aged $\geq 15$ years. The mean age $( \pm$ SD) of the respondents was 36.3 years $( \pm$ 17.1) [men: $37.3( \pm 17.9)$ vs. women $35.5( \pm 16.3)]$. The mean missing data rate was $0.7 \%$. The missing data rates were $0 \%$ for age, dwelling, literacy, SES, tobacco use and province; and $4.8 \%, 0.9 \%$, and $0.7 \%$ for marital status, hypertension and self-rated health, respectively. Majority of the respondents lived in rural areas $(64.1 \%)$, were illiterate (68.0) and belonged to either low (33.1) or middle (49.0) socioeconomic group. As much as $7.6 \%$ respondents ( 10.4 women vs. $4.6 \%$ men) were widows, widowers, separated or divorced. Data on SRH were missing for 69 individuals $(0.7 \%)$ so the final sample size was 9373 people. Of these, $65.1 \%$ respondents, $51.3 \%$ men vs. 77.2 $\%$ women, rated their health as poor/fair (Table 1 and 2). In the Punjab province, $82.6 \%$ people (69.6\% men vs. $94.6 \%$ women) perceived their health to be poor/fair. Women had, at all ages, poorer SRH than men (Figure 1). Multiple logistic regression analysis showed a significant interaction between sex and age ( $\mathrm{p}<0.0001)$; but as shown in Fig 1 the interaction was due to the gender differences only in the ages 15-19 years, whereas poor/fair $\mathrm{SRH}$ at all older ages was more prevalent among women and increased at the same rate as it did among men. There was no significant interaction for ages 20 and above $(\mathrm{p}=$ 0.26 ). Women aged 15-19 years (adjusted OR 2.79, $95 \%$ CI: $2.21-3.51)$, women aged $\geq 20$ years $(7.60,6.23-9.27)$ and men aged $\geq 20$ years(1.37, 1.14-1.64) were more likely to report having poor/fair health compared with men aged 15-19 years. Individuals living in Punjab had the highest odds (13.34, 95 \% CI: 11.63-15.29) of poor/ fair health. Other independent determinants of poor/fair health were low or middle SES, rural dwelling, literacy, and current tobacco use (Table 3).

\section{Discussion}

The prevalence of poor/fair health in Pakistan (65.1\%) is far higher than that in Japan (9.8), Canada (11.7), United States (14.5) and the UK (25.3) in almost comparably aged populations [8-11]. However, it is closer to that obtained in a study in Russia in 1996 where the prevalence was higher, mainly because of major social changes and political and economic uncertainties after the collapse of the erstwhile Soviet Union [12]. 
South Asians, regardless of whether they live in their home countries or overseas have high morbidity and mortality rates. The fourth National Survey of Ethnic Minorities (1993-1994) in the UK that assessed the association between SRH and ethnicity found that people of Pakistani and Bangladeshi origin living in the UK had the poorest $\mathrm{SRH}$, followed by Indians.

Our most striking finding was the substantially poorer health status, at all ages, of women compared to men in Pakistan. To our knowledge, this is the first study on SRH reporting a significant interaction between age and sex ( $p$ $<0.0001)$ - although the interaction was due to the gender differences only in the ages 15-19 years and not in older ages. For individuals aged $\geq 20$ years, poor/fair SRH was more prevalent among women and increased at the same rate as it did among men. A limitation of the NSHP was that it did not assess mental health status, which is an important determinant of SRH. Studies in both developed and developing countries have shown than women have a higher prevalence of depression and anxiety than men. These disparities are strongly age-related. So differences in the rates of poor/fair SRH between women and men in our analysis may be due to possible age-related sex differences in the prevalence of common mental disorders in Pakistan. According to the WHO, an important reason for why women have higher rates of depression and anxiety than men is the high rates of domestic and sexual violence to which women are increasingly subjected [13]. Violence against women is endemic in Pakistan [14]as are mental disorders such as depression and anxiety [15].

The relationship between SES and the health status is well-established [16-18] although the potential for reverse causation (people may be poor because they are ill) makes such interpretations difficult. In the NHSP, SES was determined by the number of household items owned. In our analysis, even in the adjusted model people with low and middle SES were 1.56 and 1.17 times more likely to report poor/fair health compared with their counterparts with high SES. This is consistent with the findings of a study conducted in Poland and Hungary where as the number of household items owned increased, the odds of poor health decreased [19]. It is argued that material aspects of ownership of household items are important, but equally so may be the psychosocial aspects. For example, many household items not only have a direct protective effect on health, they also are marker of a higher status in the society. They may affect psychosocial well-being by psychosocial processes [20].

Another important finding is that tobacco use was independently associated with poor/fair SRH, although the cross-sectional design of the study limits the causal interpretation of this association. Several other studies have also reported a significant association between tobacco use and suboptimal SRH [21-23]. We also found province of dwelling and rural dwelling to be independently associated with poor/fair SRH.

\section{Conclusion}

This is the first study reporting on the prevalence of and risk factor for poor/fair SRH at a population-level in a South Asian country. Our findings may be generalisable to several other countries in South Asia given similarities in physical environment, culture, socioeconomic conditions and public investment in health. The prevalence of poor/fair SRH in Pakistan is one of the worst ever reported globally, warranting immediate attention. Further research is needed to explain why women in Pakistan have, at all ages, poorer SRH than men.

\section{Competing interests}

The author(s) declare that they have no competing interests.

\section{Authors' contributions}

KA conceived the report, performed the statistical analysis, and drafted the manuscript. TJ and NC contributed to review, and to the revision of the report. All authors read and approved the final manuscript.

\section{Acknowledgements}

Supported by grants from Fogarty International Center, NIH (Drs. Jafar/ Chaturvedi). The funding source had no role in the analysis, or interpretation of the data or in the decision to submit the paper for publication. We thank members of the Pakistan Medical Research Council, and the United States Department of Health and Human Services for their assistance in acquisition of the NHSP data.

\section{References}

I. Bhutta ZA, Gupta I, de'Silva H, Manandhar D, Awasthi S, Hossain SM, Salam MA: Maternal and child health: is South Asia ready for change? Bmj 2004, 328:816-819.

2. Lawn JE, Cousens S, Bhutta ZA, Darmstadt GL, Martines J, Paul V, Knippenberg R, Fogstadt H, Shetty P, Horton R: Why are 4 million newborn babies dying each year? Lancet 2004, 364:399-40I.

3. Chaturvedi N: Ethnic differences in cardiovascular disease. Heart 2003, 89:68I-686.

4. Chandola T: Ethnic and class differences in health in relation to British South Asians: using the new National Statistics Socio-Economic Classification. Soc Sci Med 200 I, 52: I 285-1296.

5. Idler EL, Benyamini Y: Self-rated health and mortality: a review of twenty-seven community studies. J Health Soc Behav 1997, 38:2I-37.

6. Jafar TH, Chaturvedi N, Gul A, Khan AQ, Schmid CH, Levey AS: Ethnic differences and determinants of proteinuria among South Asian subgroups in Pakistan. Kidney Int 2003, 64: 1437-1444.

7. Jafar TH, Levey AS, Jafary FH, White F, Gul A, Rahbar $\mathrm{MH}$, Khan $\mathrm{AQ}$, Hattersley A, Schmid CH, Chaturvedi N: Ethnic subgroup differences in hypertension in Pakistan. J Hypertens 2003, $21: 905-912$.

8. Shibuya $\mathrm{K}$, Hashimoto $\mathrm{H}$, Yano $\mathrm{E}$ : Individual income, income distribution, and self rated health in Japan: cross sectional analysis of nationally representative sample. Bmj 2002, 324: 16-19.

9. Statistics Canada. National Population Health Survey, I99697. 
10. Kennedy BP, Kawachi I, Glass R, Prothrow-Stith D: Income distribution, socioeconomic status, and self rated health in the United States: multilevel analysis. Bmj 1998, 31 7:917-921.

II. Weich S, Lewis G, Jenkins SP: Income inequality and self rated health in Britain. J Epidemiol Community Health 2002, 56:436-44I.

12. Bobak M, Pikhart H, Hertzman C, Rose R, Marmot M: Socioeconomic factors, perceived control and self-reported health in Russia. A cross-sectional survey. Soc Sci Med 1998, 47:269-279.

13. WHO. World Health Report 2003. Shaping the future. Geneva, World Health Organization; 2003.

14. Human Rights Watch. Crime or Custom? Violence Against Women in Pakistan http://www.hrw.org/reports// 999/Pakistan [accessed August 4, 2004].

15. Mirza I, Jenkins R: Risk factors, prevalence, and treatment of anxiety and depressive disorders in Pakistan: systematic review. Bmj 2004, 328:794.

16. Smith GD, Bartley M, Blane D: The Black report on socioeconomic inequalities in health 10 years on. Bmj 1990, 301:373-377.

17. Lynch J, Smith GD, Hillemeier M, Shaw M, Raghunathan T, Kaplan G: Income inequality, the psychosocial environment, and health: comparisons of wealthy nations. Lancet 200I, 358: $194-200$

18. Carlson P: Risk behaviours and self rated health in Russia 1998. J Epidemiol Community Health 200I, 55:806-8I7.

19. Pikhart H, Bobak M, Rose R, Marmot M: Household item ownership and self-rated health: material and psychosocial explanations. BMC Public Health 2003, 3:38.

20. Marmot M, Wilkinson RG: Psychosocial and material pathways in the relation between income and health: a response to Lynch et al. Bmj 200I, 322:1233-I 236.

21. Rius C, Fernandez E, Schiaffino A, Borras JM, Rodriguez-Artalejo F: Self perceived health and smoking in adolescents. J Epidemiol Community Health 2004, 58:698-699.

22. Arday DR, Giovino GA, Schulman J, Nelson DE, Mowery P, Samet JM: Cigarette smoking and self-reported health problems among U.S. high school seniors, 1982-1989. Am J Health Promot 1995, 10:111-116.

23. Fernandez E, Schiaffino A, Rajmil L, Garcia M, Herdman M, Segura A: Re: "Health problems in teenage daily smokers versus nonsmokers, Norway, 1995-1997: the Nord-Trondelag Health Study". Am J Epidemiol 2000, I 52:395-396.

\section{Pre-publication history}

The pre-publication history for this paper can be accessed here:

http://www.biomedcentral.com/1471-2458/5/51/prepub

\section{Publish with Biomed Central and every scientist can read your work free of charge}

"BioMed Central will be the most significant development for disseminating the results of biomedical research in our lifetime. "

Sir Paul Nurse, Cancer Research UK

Your research papers will be:

- available free of charge to the entire biomedical community

- peer reviewed and published immediately upon acceptance

- cited in PubMed and archived on PubMed Central

- yours - you keep the copyright 